Review Article

\title{
Extracellular Vesicles: A Novel Target for Exercise-Mediated Reductions in Type 2 Diabetes and Cardiovascular Disease Risk
}

\author{
Natalie Z. M. Eichner, ${ }^{1}$ Uta Erdbrügger, ${ }^{2}$ and Steven K. Malin $\mathbb{D}^{1,3,4}$ \\ ${ }^{1}$ Department of Kinesiology, University of Virginia, Charlottesville, VA, USA \\ ${ }^{2}$ Division of Nephrology, University of Virginia, Charlottesville, VA, USA \\ ${ }^{3}$ Division of Endocrinology and Metabolism, University of Virginia, Charlottesville, VA, USA \\ ${ }^{4}$ Robert M. Berne Cardiovascular Research Center, University of Virginia, Charlottesville, VA, USA \\ Correspondence should be addressed to Steven K. Malin; skm6n@virginia.edu
}

Received 6 March 2018; Accepted 3 May 2018; Published 19 June 2018

Academic Editor: Rosa Fernandes

Copyright (c) 2018 Natalie Z. M. Eichner et al. This is an open access article distributed under the Creative Commons Attribution License, which permits unrestricted use, distribution, and reproduction in any medium, provided the original work is properly cited.

\begin{abstract}
Regular exercise is important for reducing type 2 diabetes (T2D) and/or cardiovascular disease (CVD) risk. However, only about $40-50 \%$ of this CVD risk reduction is accounted for by adiposity, hyperglycemia, hypertension, and dyslipidemia. Herein, we present the novel hypothesis that extracellular vesicles (EVs) are candidate biomarkers that may relate to impaired endothelial function and insulin resistance independent of obesity risk factors. EVs are small membrane-bound particles that are generated by cells following stimulation, stress, or activation. They carry markers of their parent cell and are thought to be potent bioactivators and communicators. We discuss the underlying physiology of specific cell type EVs, as well as examine how acute and chronic exercise interventions impact EV count and phenotype. We also propose that current gaps in the field are in part related to use of different detection techniques and the lack of standardized measurements of EV affecting the pre- and postanalytical phase. Ultimately, improving the understanding of how EVs impact cardiometabolic health and their function will lead to improved approaches for enhancing diagnostic options as well as designing exercise interventions that treat and/or prevent T2D and CVD.
\end{abstract}

\section{Introduction}

Nearly $33 \%$ of all deaths globally each year are attributed to cardiovascular disease (CVD) [1]. In fact, CVD mortality has increased from 12.59 to 17.82 million between 1990 and 2015 [2]. Individuals with type 2 diabetes (T2D) are 23 times more likely to have CVD than their healthy counterparts, indicating that abnormalities in glucose metabolism share a CVD pathogenic root [3]. However, glucose alone may not be a primary driver of CVD in people with T2D given recent interventions focused on lowering glucose alone have failed to significantly lower CVD risk and mortality [4]. As such, it is not surprising that elevated blood pressure and dyslipidemia in people with hyperglycemia are considered critical drivers of CVD that are linked together by insulin resistance [5]. Insulin resistance can be defined as the reduced responsiveness of skeletal muscle, liver, adipose, and vasculature to insulin for the maintenance of nutrient delivery and utilization. Although the exact cause of insulin resistance is unclear, endothelial dysfunction is a leading candidate for promoting these nutrient disturbances [6]. Endothelial function is the ability of the endothelium to respond to both metabolic mediators (e.g., insulin and nitric oxide) and/or shear stress that enhance blood flow. Recently, the American Heart Association suggested that current biomarkers (e.g., blood pressure and lipids) do not account for the majority of adverse outcomes and may account for only $40-50 \%$ of CVD risk [7]. Thus, there is an urgent need to identify new treatment targets for T2D and CVD that mediate health and well-being.

Extracellular vesicles (EVs) have emerged as novel biomarkers of T2D and CVD $[8,9]$. EVs belong to a heterogeneous population of vesicles summarized with the generic term "Extracellular Vesicles" (EVs). Interestingly, most of 


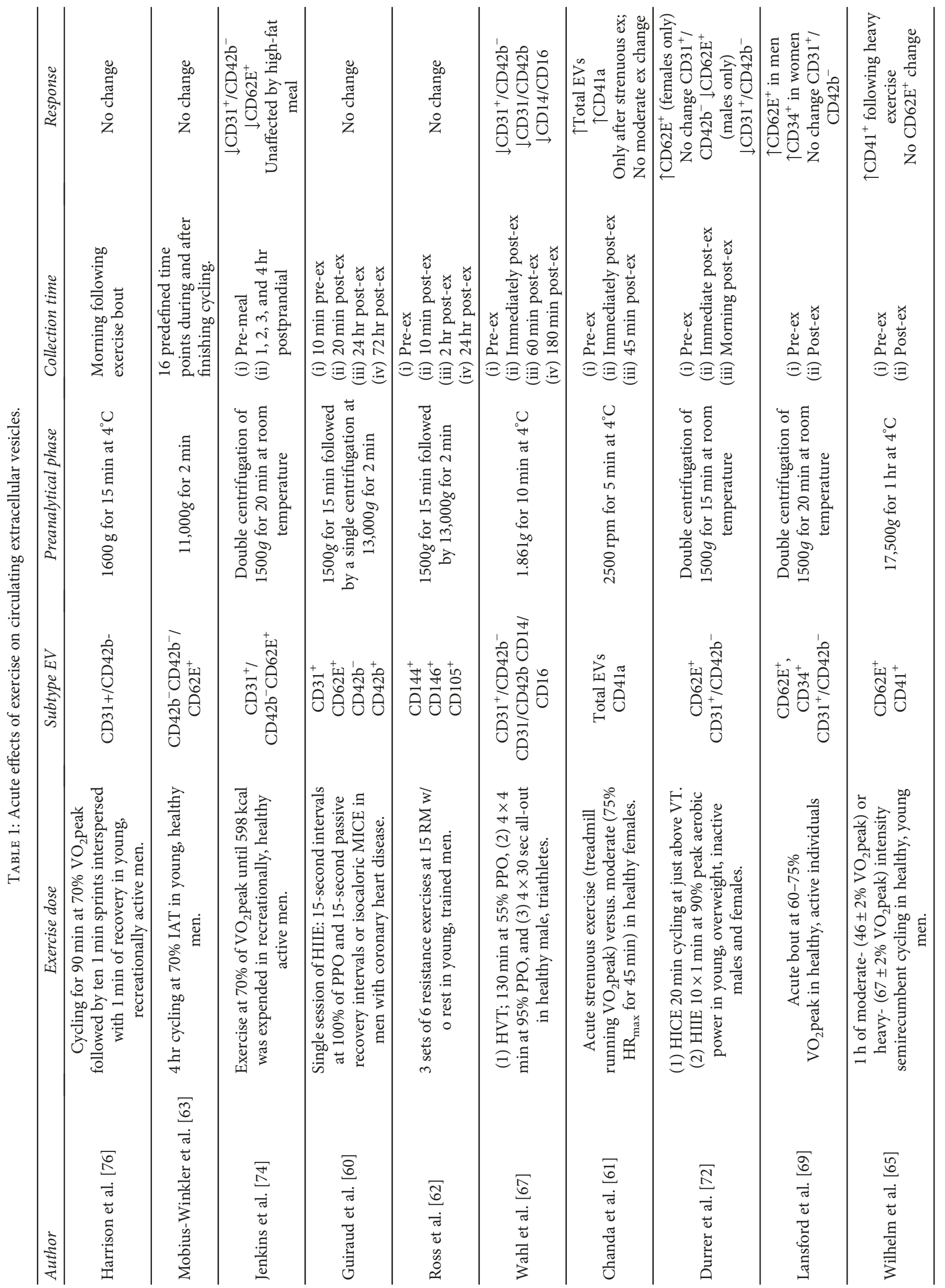




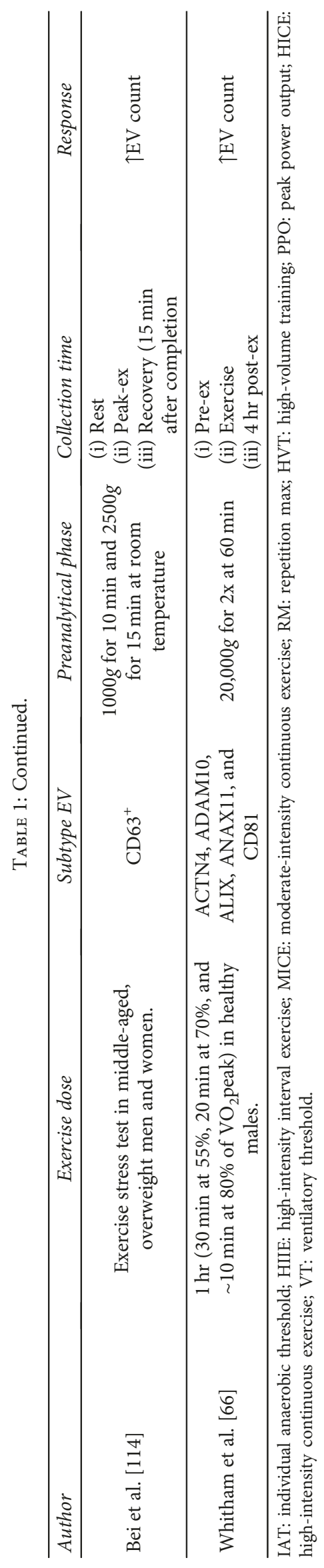




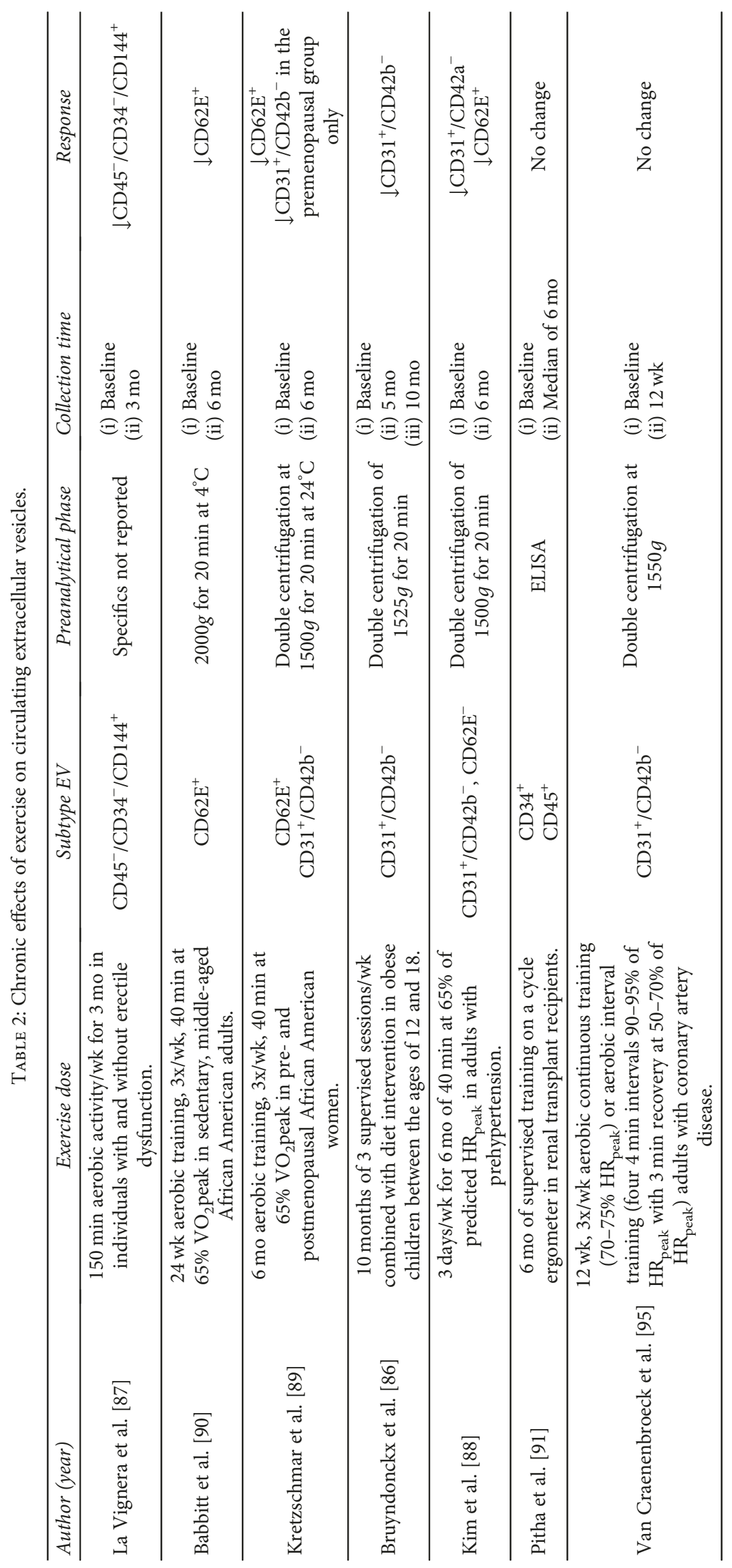


the studies analyzing EVs in metabolic diseases have focused on larger EVs (>100-1000 nm) (Tables 1 and 2, resp.), called microparticles/microvesicles, generated by the low centrifugation speed of up to $20,000 \mathrm{Gs}$, but our own data [10] and that of others [11-13] indicate that we also see smaller EVs $(<100 \mathrm{~nm}$, called exosomes) in these EV preps. As these studies have likely analyzed a mix of larger and smaller EVs of different densities, we will only use the term EV. EVs are unique biomarkers as they are also believed to carry and transfer proteins, lipids, and nucleic acids, and they facilitate communication between cells. How EVs regulate vascular health remains to be fully determined, but obesity-related insulin resistance might be a potential reason through oxidative stress and inflammatory-related mechanisms [14]. Interestingly, physical inactivity also increases EV levels in association with worsening of insulin resistance and endothelial dysfunction, suggesting that muscle contraction alters disease risk in an EV-mediated manner [15]. However, there is limited research regarding the effects of physical activity and/or exercise on EVs in healthy and disease populations. In particular, we propose that EVs may be a novel mediator of T2D and CVD risk. First, we highlight the biogenesis of EVs and the purported mechanism relating EV to insulin resistance and endothelial function. Next, we examine the gaps in knowledge regarding the effectiveness of acute and chronic exercise on EVs. We also discuss the mechanistic role of cell-specific EVs related to leukocytes, platelets, and the endothelium as mediators of cardiometabolic risk. Lastly, we analyze how current EV methodologies could play a role in discrepancies seen across exercise studies and discuss new methodology to advance understanding of EVs and exosomes that could improve diagnostic and treatment options for T2D and CVD.

\section{Extracellular Vesicle Biogenesis}

First described as merely "cell dust" by Wolf in 1967, EVs are now recognized as cell bioactivators and communicators of cardiometabolic health [16]. Smaller EVs $(<100 \mathrm{~nm}$, also called exosomes) are thought to derive from multivesicular bodies inside the cells that are then secreted into different body fluids, whereas larger EVs (>100-100 nm, also called microparticles/ microvesicles) are believed to be shed from cells into body fluids/tissue upon stimulation or activation. These larger EVs are likely the product of outward membrane budding through cytoskeletal rearrangement and a loss of calcium-dependent membrane phospholipid asymmetry [17]. These vesicles consist of membrane proteins and cytosolic material from the cell they originate from. Indeed, EVs are derived from cells in circulation (i.e., endothelial, platelet, and leukocyte), erythrocytes [18], as well as progenitor cell populations [19] (Table 3). Additionally, EVs are found in many other body fluids besides blood, including urine [20], which increase the potential for clinical collection sites. EVs are released during conditions of stress that initiate cell activation and/or apoptosis [21]. In particular, proinflammatory stimuli (e.g., oxidative stress/cytokines), bioactive lipids [22], and hyperglycemia [23] are considered key stimuli that impact EV release, phenotype, and function. In particular, hyperglycemia increases endothelium-derived EV formation, size, and reduces surface
TABLE 3: Most commonly used extracellular vesicles.

\begin{tabular}{|c|c|}
\hline EV origin & Surface markers \\
\hline Endothelium & 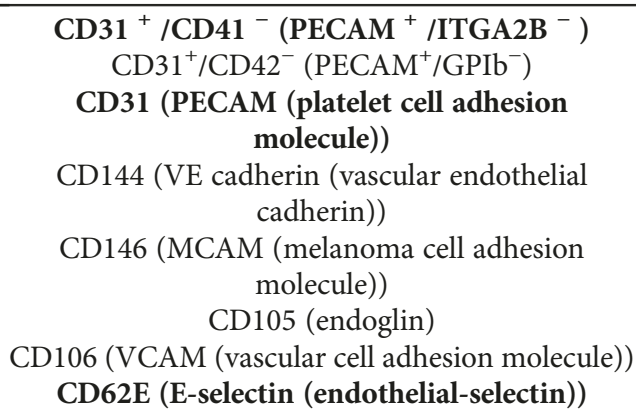 \\
\hline Platelet & $\begin{array}{c}\text { CD41 (ITGA2B (integrin alpha 2b)) } \\
\text { CD42 (GPIb (glycoprotein Ib)) } \\
\text { CD31 (PECAM (platelet cell adhesion molecule)) }\end{array}$ \\
\hline Leukocyte & $\begin{array}{c}\text { CD45 (PTPRC (protein tyrosine phosphate } \\
\text { receptor type C)) } \\
\text { CD11b (ITGAM (integrin alpha M)) } \\
\text { CD14 (coreceptor of lipopolysaccharide) } \\
\text { CD16 (on surface of neutrophils, monocytes, and } \\
\text { macrophages) } \\
\text { CD62L (L-selectin (leukocyte selectin)) }\end{array}$ \\
\hline Red blood cell & CD235 (glycophorin A) \\
\hline
\end{tabular}

charge that collectively prompt greater procoagulant activity [24]. Moreover, high glucose conditions increase NADPH oxidase activity in endothelial EVs that work to amplify the effects of oxidative stress-mediated inflammation on the endothelium [23] that decrease endothelial nitric oxide synthase (eNOS) [25], thereby potentially impairing vascular function and raising CVD risk. There is also work suggesting that EVs may not only release inflammatory cytokines [26] but also act as deliverers of bioactive lipids [22], protein, and genetic material [10] between cells. Taken together, EVs represent a potentially novel paradigm in cell-to-cell communications between various organs important for T2D and CVD. For a comprehensive discussion of biogenesis of EVs, we will refer the reader to other review papers [27].

\section{Extracellular Vesicles in The Pathogenesis of T2D and CVD}

EVs are composed of parental proteins, nucleic acids, and cytoplasm based on the stimuli [10]. This is physiologically important because carrying markers of the parent cell allows for specific subpopulation identification (e.g., endotheliumor leukocyte-derived) [10] that can influence crosstalk between tissues and cells [28]. Indeed, elevated endothelial EVs are thought to reflect vascular injury, whereas increased leukocyte and platelet EVs signify proinflammation and coagulation, respectively. This notion is consistent with literature reporting that different subtypes of EVs are elevated in people with prediabetes [29], T2D, and CVD [8, 9] as well as hypertension [30], chronic kidney disease [31], and heart failure [32]. Even obesity, independent of comorbidities, presents with elevated platelet EV levels [33] in relation to reduced fibrinolytic ability. Subsequently, these observations 


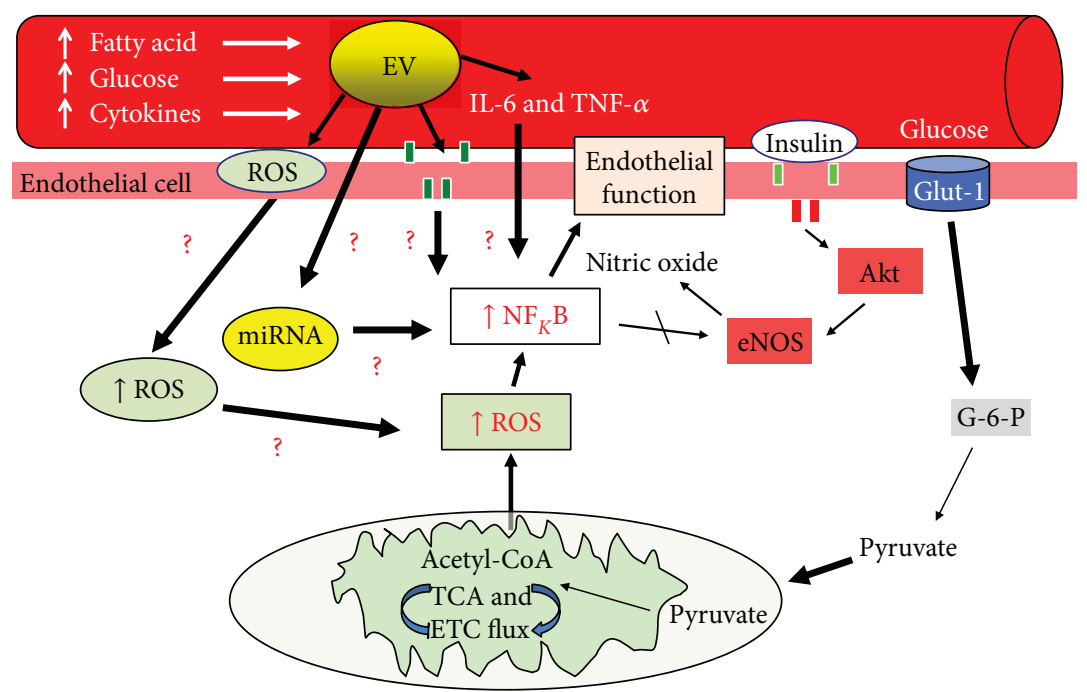

(a) Sedentary condition

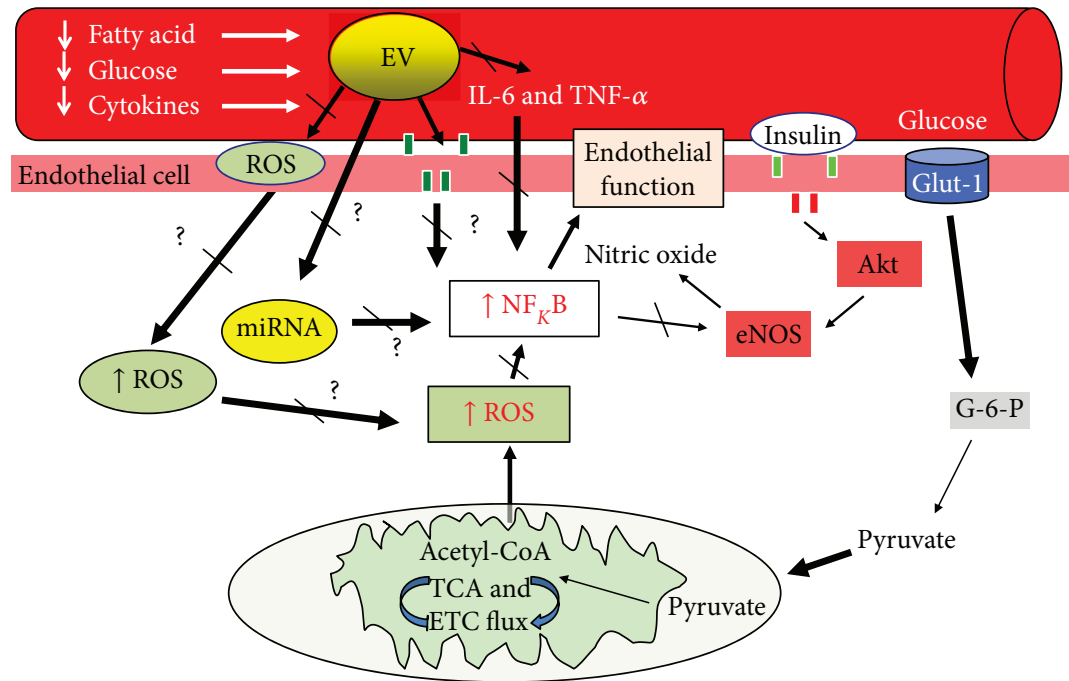

(b) Physical activity/exercise condition

Figure 1: Working hypothesis by which extracellular vesicles (EVs) interact with exercise to influence vascular function and insulin sensitivity. Reactive oxygen species (ROS) are generated by EVs in response to bioactive lipids, glucose, and inflammatory cytokines and act as important cellular regulators in cell health. In addition, EVs may bind to cells and interfere with receptor-related mechanisms and/or release microRNA (miRNA) to influence cell activity. Lastly, EVs may release inflammatory cytokines and impact cell NF $\kappa \mathrm{B}$ activity, which influences cell vascular function. Exercise (b) decreases circulatory lipids, glucose, and cytokines, thereby improving EV levels and function. We hypothesize herein that EVs not only serve as a biomarker of type 2 diabetes and cardiovascular disease but also regulate vascular function independent of traditional obesity-related risk factors. Future work should consider studying the interaction of $\mathrm{EV}$ and exercise doses in order to identify optimal treatment plans for preventing type 2 diabetes and cardiovascular disease.

support that EVs likely play a key physiologic role above and beyond a biomarker.

Circulating EVs are believed to play an important physiologic role in vascular physiology [34] (Figure 1(a)). Werner et al. reported that elevated endothelial $\mathrm{EVs}\left(\mathrm{CD} 31^{+} /\right.$ Annexin $\mathrm{V}^{+}$) are correlated with reduced endotheliumdependent vasorelaxation [35]. This is consistent with others reporting that elevations in these same endothelial EVs are related to reduced flow-mediated dilation as well as increased pulse wave velocity and carotid intima-media thickness $[36,37]$. Together, these findings suggest that higher levels of EVs relate to poor blood flow and arterial stiffness.
There are several putative mechanisms that may explain how EVs promote dysregulation of blood flow, although most data exists from in vitro experiments and more human work is needed. EVs are thought to directly produce reactive oxygen species (ROS). Endothelial EVs (CD144, Annexin V ${ }^{+\mathrm{ve}}$ ) increase production of superoxide anion and hydrogen peroxide in cultured endothelial cells through NADPH oxidase and mitochondria [38,39], although others suggest that xanthine oxidase may contribute in endothelial (CD144-PE) [40], lymphocytic (CD4, $\mathrm{CD}^{+}, \mathrm{CD} 8, \mathrm{CD} 11 \mathrm{a}$, Fas, and FasL) [41], and monocyte-derived EVs [42]. Additionally, EVs are hypothesized to promote in vivo inflammation through stimulation 
of proinflammatory cytokines and the recruitment of inflammatory cells [26]. In in vitro experiments, leukocyte EVs $\left(\mathrm{CD} 14^{+}\right)$promote the release of IL-6 and IL-8 in cultured endothelial cells [43]. In addition, T-cell EVs promote TNF- $\alpha$ and IL-1b by monocytes [44] and promote the interaction and adhesion of leukocytes to endothelial cells [22]. These later findings are consistent with work by Mastronardi et al. [45] demonstrating that injection of EVs from blood of patients with sepsis into mice promotes increased expression of iNOS, COX-2, and $\mathrm{NF} \kappa \mathrm{B}$ in the heart and lung, thereby supporting a direct role of EVs at producing inflammation. Lastly, circulating EVs express the functionally active eNOS protein [25]. This is clinically germane as patients with endothelial dysfunction have EVs with reduced expression and release of nitric oxide [25].

Another possible mechanism by which EVs contribute to T2D and CVD relates to the interaction and transfer of EV contents to the cell (Figure 1(a)). EVs have been proposed to physically alter cell target receptors that modify signal transmission. For example, blocking EGF receptors in endothelial cells inhibits EV-mediated ROS production and inflammation [38]. Additionally, other work has suggested that EVs from obese subjects reduce insulin-stimulated glucose uptake [46] and macrophage-derived EVs (M0 THP-1) interfere with GLUT-4 translocation in human adipocytes by decreasing pAkt, thereby inducing insulin resistance [47]. The exact cause of this insulin resistance remains to be elucidated, but activation of $\mathrm{NF} \kappa \mathrm{B}$ was noted, suggesting that inflammation may play a role. Indeed, it is also possible that miRNA transcripts from EVs also play an important role in communicating signals to local and systemic tissues for the alteration of cell activity [48]. For instance, Rautou et al. [18] demonstrated that EVs $\left(\mathrm{CD} 31^{+}\right)$derived from apoptotic plaques transferred ICAM-1 to endothelial cells, suggesting that EVs play an important inflammatory response mechanism in atherosclerosis. In addition to ICAM-1, other studies have reported adipocytederived EVs $\left(\mathrm{CD}^{+} 4^{+}\right)$to interfere with insulin signaling in both the liver [49] and skeletal muscle [50] via transfer of adipokine content, thereby inducing insulin resistance [46]. However, not all studies support the observation that EVs fuse and transfer content to cells [51], as there are different ways in which EVs promote cell-to-cell communication or even EV uptake [52]. In either case, EVs appear to mediate angiogenesis and induce endothelial repair [34, 53-55] by at least partially [56] vascular endothelial growth factor-A [57] or eNOS [25]. In this way, EVs may promote increased angiogenesis and blood flow via cargo such as eNOS-induced nitric oxide. In turn, this compensatory response of increased blood flow may allow nutrient delivery to tissue, thereby contributing to insulin-mediated GLUT-4 translocation. Given the literature linking oxidative stress and inflammation to the pathogenesis of insulin resistance and endothelial dysfunction [58], the identification of how EVs may be modified or targeted for metabolic health warrants attention.

\section{Effects of Acute Exercise Bouts on Extracellular Vesicles}

A majority of the chronic exercise training induced an effect on insulin resistance and endothelial function is considered to be the result of the last bout of exercise [59]. Subsequently, understanding the acute exercise effect on EVs provides insight independent of cardiorespiratory fitness adaptation and weight/fat loss. However, to date there are limited studies examining the effects of acute aerobic $[60,61]$ or resistance exercise [62] on EVs (Table 1). For instance, MobiusWinkler et al. tested the effect of a $4 \mathrm{hr}$ cycling protocol at $70 \%$ of the anaerobic threshold in 18 young, lean, healthy males [63] and found no change in endothelial EVs $\left(\mathrm{CD} 42 \mathrm{~b}^{-}, \mathrm{CD}_{42} \mathrm{~b}^{-} / \mathrm{CD} 2 \mathrm{E}^{+}\right)$in the immediate postexercise period, despite increases in cytokine IL-6. It was speculated that the lack of exercise effect might have been due to the population studied (healthy versus diseased) or the low to moderate intensity exercise prescribed. We add to this by speculating that the lack of EV differences following exercise could also be related to technical differences of EV detection. Blood was collected and EV pellet was enriched from platelet-poor plasma using conventional flow cytometry. Smaller EVs (e.g., $<500 \mathrm{~nm}$ ) might not have also been captured with this approach. In addition, targeted phenotyping was limited to detection of the surface marker for CD62E and CD42. CD62E is found on activated endothelium, but other endothelial markers might reflect better the endothelial changes during exercise. Nonetheless, these findings are consistent with Guiraud et al. who showed that there was no change in endothelial EVs $\left(\mathrm{CD} 31^{+}, \mathrm{CD}_{2} \mathrm{E}^{+}\right.$, and $\left.\mathrm{CD} 42 \mathrm{~b}^{-}\right)$ or platelet EVs $\left(\mathrm{CD} 42 \mathrm{~b}^{+}\right)$in 19 male coronary heart disease patients when measured up to $72 \mathrm{hr}$ following either highintensity interval or moderate-intensity cycling exercise [60]. In contrast, Chanda et al. reported that a maximal bout of exercise (defined as a $\mathrm{VO}_{2}$ max test) elicited an approximate $40 \%$ increase in platelet (CD41a) EVs in healthy adults [61]. While these later findings suggest that exercise intensity raises EV, it should be noted that maximal exercise would be considered a stressful perturbation to the system and it is known that high-intensity exercise raises oxidative stress and inflammation in the immediate postexercise period, thereby conferring a stimulus for metabolic adaptation [64]. Indeed, in vitro experiments by Wilhelm et al. demonstrate that EVs generated after intense exercise in healthy young men enhanced endothelial proliferation, migration, and tubule formation compared with $\mathrm{EV}$ derived from the rest [65]. Interestingly, platelet $\mathrm{EVs}\left(\mathrm{CD} 41^{+}\right)$from the same patients were elevated during $1 \mathrm{hr}$ of high $\left(67 \% \mathrm{VO}_{2} \max \right)$, but not moderate $\left(46 \% \mathrm{VO}_{2} \max \right)$, intensity exercise. These later findings are of potential significance as they suggest that exercise intensity promotes angiogenesis for improved blood flow and nutrient delivery. Whether EVs from people with $\mathrm{T} 2 \mathrm{D}$ or CVD respond to exercise comparably to lean healthy people remains to be seen. This is particularly of interest given recent work highlighting that single bouts of exercise increase EVs (ACTN4, ADAM10, ALIX, ANAX11, and CD81) and miRNA to potentially coordinate communication of nutrient homeostasis between muscle, endothelium, as well as liver $[66,67]$.

Another possible reason explaining why acute exercise has yielded equivocal EV results may relate to sex differences. Toth et al. reported elevated total Annexin V EV, platelet EV (CD63, P-selectin-exposing), and endothelial EV (CD62, 
E-selectin-exposing) in 27 young healthy women compared to men while at rest. It was reported that elevated EVs (Annexin V-binding EV, CD61, P-selectin-exposing EV, and E-selectin-exposing EV) in women were related to the menstrual luteal cycle [68]. However, no significant sex- or menstrual cycle-dependent differences were observed in the endothelial EV (CD144 ${ }^{+}$). Lansford et al. [69] recently tested the effect of an acute bout of exercise $\left(60-75 \% \mathrm{VO}_{2} \max \right)$ on endothelial EVs (CD62 $\left.\mathrm{E}^{+}, \mathrm{CD}^{+} 1^{+} / \mathrm{CD}_{2} 2 \mathrm{~b}^{-}, \mathrm{CD} 34^{+}\right)$in recreationally active men and women and demonstrated that endothelial EV $\left(\mathrm{CD}^{2} \mathrm{E}^{+}\right)$increased by $107 \%$ in men but not in women. Conversely, women displayed a $253 \%$ elevation in mononuclear EVs $\left(\mathrm{CD} 34^{+}\right)$. Based on previous research $[70,71]$, these results suggest that increased levels may prime $\mathrm{CD}_{3}{ }^{+}$peripheral blood mononuclear cells for paracrine angiogenic effects in females. Interestingly, the endothelial EVs $\left(\mathrm{CD} 31^{+} / \mathrm{CD} 42 \mathrm{~b}^{-}\right)$remained unchanged following exercise in either sex. These results suggest that only certain phenotypes of endothelial EVs $\left(\mathrm{CD} 2 \mathrm{E}^{+}\right)$or other not yet tested $\mathrm{EV}$ phenotypes may be affected by sex and exercise. In another study, Durrer et al. examined the effects of highintensity continuous versus interval exercise on EVs in young, overweight inactive adults and reported that both exercises lowered EVs in men $(n=6)$, but endothelial EV counts $\left(\mathrm{CD} 31^{+} / \mathrm{CD} 42 \mathrm{~b}^{-}\right)$were unaffected in females $(n=7)$ [72]. However, high-intensity continuous exercise increased endothelial EVs $\left(\mathrm{CD} 6 \mathrm{E}^{+}\right)$in females. Although this was a relatively small sample size, the data suggest that sex may be an important factor explaining differential EV responses to exercise. Further work is needed to elucidate the mechanism by which men and women differ in $\mathrm{EV}$ profiles in order to individualize exercise to treat and/or prevent disease.

It reasons that dietary intake may also influence EV responses postexercise since circulating bioactive lipids are considered a stimulus for EV biogenesis. In fact, high-fat meals induce endothelial dysfunction in healthy and T2D individuals [73]. Although Jenkins et al. reported that a high-fat meal had no independent effect on endothelial EVs, acute exercise at $70 \% \quad \mathrm{VO}_{2} \max$ lowered endothelial EVs $\left(\mathrm{CD}_{2} 2 \mathrm{E}^{+}\right.$and $\mathrm{CD}^{+} 1^{+} / \mathrm{CD}_{2} 2 \mathrm{~b}^{-}$) by $55 \%$ and $30 \%$, respectively (both $P<0.05)$ compared to a sedentary control in healthy, recreationally active men [74]. Interestingly, the lowering of endothelial EVs $\left(\mathrm{CD}_{2} 2 \mathrm{E}^{+}\right.$and $\left.\mathrm{CD} 31^{+} / \mathrm{CD} 42 \mathrm{~b}^{-}\right)$postexercise was associated with blunted ROS production during postprandial lipemia. This finding supports the notion that EVs may induce vascular dysfunction through an oxidative stress-mediated mechanism. The modulation of oxidative stress postexercise may also be clinically relevant since it relates to fasting and postprandial endothelial dysfunction in obese individuals with prediabetes [75]. In addition, a lowering of endothelial EVs $\left(\mathrm{CD} 31^{+}, \mathrm{CD} 31^{+} / \mathrm{CD}_{2} 2 \mathrm{~b}^{-}\right)$, which may be indicative of endothelial activation and apoptosis, suggests that exercise confers cardiovascular protection through modulation of the EV phenotype. However, Harrison et al. reported that high-intensity exercise performed at $\sim 70 \%$ $\mathrm{VO}_{2}$ max for $90 \mathrm{~min}$ had no effect on high-fat-fed-induced elevations in endothelial EVs $\left(\mathrm{CD} 31^{+} / \mathrm{CD}_{2} 2 \mathrm{~b}^{-}\right)$in recreationally active young men [76]. This observation is in stark contrast to Jenkins et al. [74]. Despite both studies prescribing exercise at
$70 \% \mathrm{VO}_{2} \max$, Harrison et al. included ten 1 min sprints. This subtle difference in exercise protocols may be of relevance since high-intensity exercise could have promoted greater vascular injury and prohibited the lowering of EVs. Additionally, differences in EV preparation and analysis, such as centrifugation at $1500 \mathrm{~g}$ for $20 \mathrm{~min}$ at room temperature [74] as opposed to $1600 \mathrm{~g}$ for $15 \mathrm{~min}$ at $4^{\circ} \mathrm{C}$ [76], may account for differences between the two studies. In either case, additional work is required to determine if exercise restores dietinduced EV levels to optimize exercise prescription for disease prevention in men and women given that postprandial metabolism is a strong predictor of CVD [77].

\section{Effects of Chronic Exercise Training on Extracellular Vesicles}

Exercise training improves whole body insulin sensitivity [78, $79]$ and glucose tolerance $[80,81]$ in adults with prediabetes and T2D. Additionally, chronic exercise enhances endothelial function in healthy individuals [82] and those at risk for [83] or with CVD $[84,85]$. Therefore, it would be expected that long-term exercise training would also have favorable effects on EV phenotype and count. Bruyndonckx et al. recently demonstrated that 10 months of exercise training significantly decreased endothelial EVs $\left(\mathrm{CD} 31^{+} / \mathrm{CD} 42 \mathrm{~b}^{-}\right)$as measured by conventional flow cytometry in 33 overweight children [86]. In addition to decreasing endothelial EVs, exercise training significantly improved microvascular function (measured via pulse amplitude tonometry), increased circulating adiponectin, and reduced body fat and high-sensitivity C-reactive protein. These findings are consistent with other work reporting that 12-24 weeks of aerobic exercise with weight loss significantly lowered endothelial EVs $\left(\mathrm{CD} 31^{+} / \mathrm{CD} 41 \mathrm{a} ; \mathrm{CD}_{2} \mathrm{E}^{+}\right)$in middle-aged men with erectile dysfunction [87] or prehypertensive men and women [88], as well as in African American women $[89,90]$ (Table 2). Interestingly, changes in endothelial EVs (CD62E $\left.{ }^{+}\right)$, IL-6, and IL-10 accounted for nearly $11 \%$ of the improvements in flow-mediated dilation following exercise training in the later studies [89, 90].

Although exercise training appears to favorably lower endothelial EVs $\left(\mathrm{CD} 31^{+} / \mathrm{CD} 41 \mathrm{a} ; \mathrm{CD} 6 \mathrm{E}^{+}\right)$, not all individuals appear to respond the same [91]. Kretzschmar et al. [89] demonstrated that endothelial EVs (CD31 $\left.{ }^{+} / \mathrm{CD} 42 \mathrm{~b}\right)$ only decreased in premenopausal compared with postmenopausal women following exercise training. It is not clear why postmenopausal women did not respond to exercise, but it is consistent with work suggesting some individuals are "exercise resistant" [75]. Another plausible reason may relate to the notion that estrogen provides protective heart effects and lowers CVD risk in women [93]. Notwithstanding these hormonal differences across the lifespan in women or compared with men, fitness may be an additional determinant of EV improvement posttraining. Indeed, recent work by our group [94], following minimal requirements of EV detection and functional studies established by the International Society of Extracellular Vesicles [12], as well as advanced imaging flow cytometry (see below for details), showed that EVs correlate with aerobic fitness and other cardiometabolic health factors in obese adults, highlighting again the potential 
role of fitness in modulating EVs. Furthermore, Van Craenenbroeck et al. reported that preintervention endothelial EVs $\left(\mathrm{CD} 31^{+} / \mathrm{CD} 42 \mathrm{~b}\right)$ count significantly predicted improvements in $\mathrm{VO}_{2}$ max despite no effect of a 12-week training program on these EVs in 200 individuals with coronary artery disease [95]. Together, these later findings suggest that EV may modulate training responses through a yet to be defined mechanism.

As exercise training promotes weight loss and decreases adipose-derived inflammation [96, 97], it is reasonable to expect that habitual exercise improves EVs originating from platelets and leukocytes. Murakami et al. reported that platelet EVs $\left(\mathrm{CD} 41^{+}\right)$were significantly correlated with a subcutaneous fat area in 49 obese, nondiabetic subjects following 12 weeks of a restricted caloric diet or a restricted caloric diet plus exercise [33]. Although EVs did not correlate with visceral fat, which is considered a chief site for inflammatory production, this finding is reasonable since subcutaneous tissue is a primary supplier of free fatty acids, and elevated free fatty acids may act as a bioactive lipid that stimulates coagulation and platelet recruitment [98]. Whether exercise or exercise plus diet alter free fatty acid mediated EV levels or function waits to be tested. In either case, in the only studies to investigate exercise on leukocyte EVs $\left(\mathrm{CD} 16^{+}, \mathrm{CD} 14^{+}\right)$, it was shown that training decreases neutrophil- and monocyte-derived EVs $\left(\mathrm{CD} 16^{+}, \mathrm{CD} 14^{+}\right)$. This observation highlights that exercise has multicell EV effects that may favor improvement in cardiometabolic health $[99,100]$.

\section{Extracellular Vesicle Analysis and Gaps}

To date, most exercise studies lack sensitivity to optimally enrich and phenotype EVs. A leading challenge in doing so is the lack of consensus on the nomenclature of EVs as well as the precise detection method or sample preparation (i.e., the preanalytical phase) $[12,101]$. In fact, the preanalytical phase includes several important steps that could impact the clarity and precision of results, including but not limited to blood collection technique (e.g., needle size or blood draw rate that impacts shear stress), sample centrifugation, timing of sample processing, sample freezing, thawing, and storage [102]. Generally speaking, EVs collected from fresh blood is considered more accurate and reflective true in vivo EV levels when compared with frozen samples [101, 103], but plasma frozen for only $24 \mathrm{hr}$ may yield comparable counts when compared to fresh sample [104]. In either case, it is suggested that samples should be analyzed after the same "freezing period" [105] to enhance accuracy of sample analysis. Centrifugation speed crucially affects the type of EV population isolated. Most of the studies analyzing EVs in exercise interventions have utilized low centrifugation speeds (Tables 1 and 2, resp.). As different speeds are used, they have likely isolated different EV populations. In addition, they might have enriched for larger EVs and therefore used the term microparticles. However, this topic is still in debate and our work [10,94] and that of others [11-13] indicates that we also see smaller EVs (e.g., exosomes, $<100 \mathrm{~nm}$ ) in these preparations, thereby making it difficult to distinguish between various types of EVs [11].
Conventional flow cytometry is the most commonly used technique for phenotyping and enumeration of EVs [106]. However, many older flow cytometer models limit the detection of smaller EVs, thereby contributing to potential gaps in our understanding of all subtypes of EVs [10]. Indeed, recent evidence suggests that while $>80 \%$ of EVs are $<500 \mathrm{~nm}$, most conventional flow cytometers have a detection threshold greater than $500 \mathrm{~nm}$, suggesting that a vast majority of EVs may not be quantified [107] with this technique. To address this discrepancy, an alternative approach has been developed, combining flow cytometry with imaging (called imaging flow cytometry). Erdbrügger et al. found that by adding imaging to flow cytometry, EVs can be clearly differentiated from the beads and cells, as well as debris. It also provides the advantage of confirming the presence of these vesicles based not only on fluorescence but also on scatter and morphology as well [108]. By detection of EV fluorescence only, even smaller EVs can be detected. The detection threshold is likely down to $100-200 \mathrm{~nm}$. To date though, no prospective exercise research exists utilizing this approach to assess $\mathrm{EV}$ phenotypes. As interest in the role of EVs as mediators and markers of disease continues to grow, implementation of standardized EV approaches will be needed to elucidate the exact role of EVs in chronic disease. One approach to close this method gap is that future studies consider using established guidelines by the EV-TRACK Consortium to improve transparency in reporting EV research [106] and follow minimal experimental requirements for definition of EVs and their functions, as published by the International Society for Extracellular Vesicles [12]. Finally, implementation of these minimal experimental requirements described [12] is crucial in moving forward with functional studies combined with content analysis (genetic, proteomic, and metabolomics) in order to better advance our understanding preventing/treating chronic disease in relation to EVs.

\section{Analysis of Smaller Extracellular Vesicles}

Most of the studies discussed so far have used low centrifugation speeds to enrich for EVs, but likely analyzed a mix of large and smaller vesicles in their preparations. A few studies have focused on use of high centrifugation speed of $100,000 \mathrm{G}$ to enrich for smaller EVs called exosomes. It is important to study all subtypes of EVs given that they play roles in immune modulation $[109,110]$, activating tissue repair [111], and angiogenesis as the following studies demonstrate. Interestingly, Fruhbeis et al. was one of them to report that cycling exercise increased smaller EVs (called exosomes, positive for Flot1, Hsp/Hsc70, and Int $\alpha \mathrm{IIb}$ ) to a greater extent when compared to treadmill exercise, but the rise in these smaller EVs (exosomes) remained elevated for a longer period of time into recovery with treadmill exercise [112]. The reason for these differential responses between treadmill and cycling exercise is not clear, but it might relate to the higher heart rate and eccentric muscle contraction associated with running. This would be consistent with prior work [65], suggesting that EVs are important for vascular repair and adaptation. Moreover, recent work from Safdar et al. has suggested that smaller EVs (exosomes) may be 
essential following endurance-oriented exercise as a means to treat metabolic disease [113]. This assertion is supported by evidence from Bei et al. who demonstrated that exerciseinduced increases in circulating EVs enhanced the protective effects of endogenous EVs against cardiac ischemia/reperfusion injury [114]. These later findings are consistent with new work highlighting that exosomes play critical roles in interorgan crosstalk during exercise to regulate energy homeostasis [66]. Taken together, these preliminary data suggest more work is needed to characterize all subtypes of EVs, including smaller (exosomes) and larger (microparticle) EVs in people with T2D and CVD following different doses of exercise, with or without diet modification, to improve clinical practice for patient care.

\section{Conclusion and Clinical Perspectives}

The precise mechanism by which exercise lowers CVD is unclear, as only $40-50 \%$ of the reduction in CVD risk in subjects reporting $>1500 \mathrm{kcal} /$ week of exercise is attributed to nontraditional CVD risk factors [115]. EVs have emerged as novel markers of T2D and CVD that have potential functional and therapeutic benefit by transferring proteins, lipids, and nucleic acids. In fact, EV physiology appears critical towards the production of oxidative stress [54], inflammation [23], and/or physical contact/release of signaling molecules (i.e., miRNA) that modulate endothelial function [116]. Herein, we present evidence that suggests EVs represent a potentially novel mechanism by which exercise could fill a "cardio-protection risk gap." Exercise may impact EVs by not only reducing substrates thought to drive EV functional responses but also altering the release of oxidative stress, inflammatory cytokines, and miRNA (Figure 1). Indeed, the acute effects of exercise on EVs are limited to endothelium-derived $\mathrm{EVs}\left(\mathrm{CD}_{2} \mathrm{E}^{+}, \mathrm{CD} 31^{+} / \mathrm{CD} 42 \mathrm{~b}^{-}\right.$, $\mathrm{CD} 144^{+}$) with little change or slight increases and few to no work on platelet- or leukocyte-derived EVs (Table 1). In contrast, exercise training appears to have more robust effects on decreasing endothelium-, platelet-, and leukocyte-derived EVs in men and women (Table 2). However, these studies are limited in that conventional flow cytometry has been used, thereby providing less sensitivity to detecting a variety of EV sizes $(<500 \mathrm{~nm})$ as well as distinguishing EVs from small cells/debris. Further work is needed using various tools including imaging or high-resolution flow cytometry, tunable resistive pulse sensing, or nanoparticle tracking device and electron microscopy before and after exercise interventions in order to ascertain a comprehensive EV profile in adults at risk for and with T2D or CVD. Knowledge of EV content and function may ultimately lead to improved patient care by enabling health care providers to provide bioengineered agents that mitigate "cargo" released from these EVs and/or deliver exercise-derived EVs as therapeutic options for optimization of T2D and CVD management.

\section{Abbreviations}

EVs: Extracellular vesicles

T2D: Type 2 diabetes
CVD: Cardiovascular disease.

\section{Conflicts of Interest}

All authors declare that they have no competing interests.

\section{Authors' Contributions}

Natalie Z. M. Eichner and Steven K. Malin were primarily responsible for writing the manuscript. Uta Erdbrügger reviewed and edited the manuscript.

\section{Acknowledgements}

The authors thank members of the Applied Metabolism \& Physiology Laboratory for helpful discussion on the manuscript.

\section{References}

[1] Centers for Disease Control and Prevention (CDC), National Diabetes Fact Sheet: National Estimates and General Information on Diabetes and Prediabetes in the United States, 2011, vol. 201, US Department of Health and Human Services, Centers for Disease Control and Prevention, Atlanta, GA, USA, 2011.

[2] G. A. Roth, C. Johnson, A. Abajobir et al., "Global, regional, and national burden of cardiovascular diseases for 10 causes, 1990 to 2015," Journal of the American College of Cardiology, vol. 70, no. 1, pp. 1-25, 2017.

[3] N. J. Morrish, S.-L. Wang, L. K. Stevens, J. H. Fuller, H. Keen, and WHO Multinational Study Group, "Mortality and causes of death in the WHO Multinational Study of Vascular Disease in Diabetes," Diabetologia, vol. 44, Supplement 2, pp. S14-S21, 2001.

[4] W. Duckworth, C. Abraira, T. Moritz et al., "Glucose control and vascular complications in veterans with type 2 diabetes," New England Journal of Medicine, vol. 360, no. 2, pp. 129139, 2009.

[5] M. Abdul-Ghani, R. A. DeFronzo, S. Del Prato, R. Chilton, R. Singh, and R. E. J. Ryder, "Cardiovascular disease and type 2 diabetes: has the dawn of a new era arrived?," Diabetes Care, vol. 40, no. 7, pp. 813-820, 2017.

[6] L. Zhang, M. A. Vincent, S. M. Richards et al., "Insulin sensitivity of muscle capillary recruitment in vivo," Diabetes, vol. 53, no. 2, pp. 447-453, 2004.

[7] P. M. Ridker, J. E. Buring, N. Rifai, and N. R. Cook, “Development and validation of improved algorithms for the assessment of global cardiovascular risk in women: the Reynolds Risk Score," JAMA, vol. 297, no. 6, pp. 611-619, 2007.

[8] N. Amabile, P.-E. Rautou, A. Tedgui, and C. M. Boulanger, "Microparticles: key protagonists in cardiovascular disorders," Seminars in Thrombosis and Hemostasis, vol. 36, no. 8, pp. 907-916, 2010.

[9] S. Nomura, "Dynamic role of microparticles in type 2 diabetes mellitus," Current Diabetes Reviews, vol. 5, no. 4, pp. 245-251, 2009.

[10] U. Erdbrügger and J. Lannigan, "Analytical challenges of extracellular vesicle detection: a comparison of different techniques," Cytometry Part A, vol. 89, no. 2, pp. 123134,2016 
[11] K. W. Witwer, E. I. Buzas, L. T. Bemis et al., "Standardization of sample collection, isolation and analysis methods in extracellular vesicle research," Journal of Extracellular Vesicles, vol. 2, no. 1, p. 20360, 2013.

[12] J. Lötvall, A. F. Hill, F. Hochberg et al., "Minimal experimental requirements for definition of extracellular vesicles and their functions: a position statement from the International Society for Extracellular Vesicles," Journal of Extracellular Vesicles, vol. 3, no. 1, 2014.

[13] J. Kowal, G. Arras, M. Colombo et al., "Proteomic comparison defines novel markers to characterize heterogeneous populations of extracellular vesicle subtypes," Proceedings of the National Academy of Sciences of the United States of America, vol. 113, no. 8, pp. E968-E977, 2016.

[14] F. Santilli, R. Liani, P. Di Fulvio et al., "Increased circulating resistin is associated with insulin resistance, oxidative stress and platelet activation in type 2 diabetes mellitus," Thrombosis and Haemostasis, vol. 116, no. 12, pp. 1089-1099, 2016.

[15] N. M. Navasiolava, F. Dignat-George, F. Sabatier et al., "Enforced physical inactivity increases endothelial microparticle levels in healthy volunteers," American journal of Physiology-Heart and Circulatory Physiology, vol. 299, no. 2, pp. H248-H256, 2010.

[16] P. Wolf, "The nature and significance of platelet products in human plasma," British Journal of Haematology, vol. 13, no. 3, pp. 269-288, 1967.

[17] B. Hugel, M. C. Martinez, C. Kunzelmann, and J. M. Freyssinet, "Membrane microparticles: two sides of the coin," Physiology, vol. 20, no. 1, pp. 22-27, 2005.

[18] P. E. Rautou, A. S. Leroyer, B. Ramkhelawon et al., "Microparticles from human atherosclerotic plaques promote endothelial ICAM-1-dependent monocyte adhesion and transendothelial migration," Circulation Research, vol. 108, no. 3, pp. 335-343, 2011.

[19] M. Pirro, G. Schillaci, F. Bagaglia et al., "Microparticles derived from endothelial progenitor cells in patients at different cardiovascular risk," Atherosclerosis, vol. 197, no. 2, pp. 757-767, 2008.

[20] D. M. Smalley, N. E. Sheman, K. Nelson, and D. Theodorescu, "Isolation and identification of potential urinary microparticle biomarkers of bladder cancer," Journal of Proteome Research, vol. 7, no. 5, pp. 2088-2096, 2008.

[21] C. M. Boulanger, "Microparticles, vascular function and hypertension," Current Opinion in Nephrology and Hypertension, vol. 19, no. 2, pp. 177-180, 2010.

[22] O. P. Barry, D. Pratico, J. A. Lawson, and G. A. FitzGeraldTranscellular activation of platelets and endothelial cells by bioactive lipids in platelet microparticles," The Journal of Clinical Investigation, vol. 99, no. 9, pp. 2118-2127, 1997.

[23] F. Jansen, X. Yang, B. S. Franklin et al., "High glucose condition increases NADPH oxidase activity in endothelial microparticles that promote vascular inflammation," Cardiovascular Research, vol. 98, no. 1, pp. 94-106, 2013.

[24] D. Burger, M. Turner, F. Xiao, M. N. Munkonda, S. Akbari, and K. D. Burns, "High glucose increases the formation and pro-oxidative activity of endothelial microparticles," Diabetologia, vol. 60, no. 9, pp. 1791-1800, 2017.

[25] P. Horn, M. M. Cortese-Krott, N. Amabile et al., "Circulating microparticles carry a functional endothelial nitric oxide synthase that is decreased in patients with endothelial dysfunction," Journal of the American Heart Association, vol. 2, no. 1, article e003764, 2012.

[26] G. Y. Chen and G. Nuñez, "Sterile inflammation: sensing and reacting to damage," Nature Reviews Immunology, vol. 10, no. 12, pp. 826-837, 2010.

[27] E. R. Abels and X. O. Breakefield, "Introduction to extracellular vesicles: biogenesis, RNA cargo selection, content, release, and uptake," Cellular and Molecular Neurobiology, vol. 36, no. 3, pp. 301-312, 2016.

[28] P. Bastos-Amador, B. Perez-Cabezas, N. Izquierdo-Useros et al., "Capture of cell-derived microvesicles (exosomes and apoptotic bodies) by human plasmacytoid dendritic cells," Journal of Leukocyte Biology, vol. 91, no. 5, pp. 751-758, 2012.

[29] A. Giannella, C. M. Radu, L. Franco et al., "Circulating levels and characterization of microparticles in patients with different degrees of glucose tolerance," Cardiovascular Diabetology, vol. 16, no. 1, p. 118, 2017.

[30] J.-M. Wang, C. Su, Y. Wang et al., "Elevated circulating endothelial microparticles and brachial-ankle pulse wave velocity in well-controlled hypertensive patients," Journal of Human Hypertension, vol. 23, no. 5, pp. 307-315, 2009.

[31] N. Amabile, A. P. Guerin, A. Tedgui, C. M. Boulanger, and G. M. London, "Predictive value of circulating endothelial microparticles for cardiovascular mortality in end-stage renal failure: a pilot study," Nephrology, Dialysis, Transplantation, vol. 27, no. 5, pp. 1873-1880, 2012.

[32] T. Nozaki, S. Sugiyama, K. Sugamura et al., "Prognostic value of endothelial microparticles in patients with heart failure," European Journal of Heart Failure, vol. 12, no. 11, pp. 1223-1228, 2010.

[33] T. Murakami, H. Horigome, K. Tanaka et al., "Impact of weight reduction on production of platelet-derived microparticles and fibrinolytic parameters in obesity," Thrombosis Research, vol. 119, no. 1, pp. 45-53, 2007.

[34] F. Dignat-George and C. M. Boulanger, "The many faces of endothelial microparticles," Arteriosclerosis, Thrombosis, and Vascular Biology, vol. 31, no. 1, pp. 27-33, 2011.

[35] N. Werner, S. Wassmann, P. Ahlers, S. Kosiol, and G. Nickenig, "Circulating CD $31^{+} /$annexin $\mathrm{V}^{+}$apoptotic microparticles correlate with coronary endothelial function in patients with coronary artery disease," Arteriosclerosis, Thrombosis, and Vascular Biology, vol. 26, no. 1, pp. 112116, 2006.

[36] C.-H. Yun, K. H. Jung, K. Chu et al., "Increased circulating endothelial microparticles and carotid atherosclerosis in obstructive sleep apnea," Journal of Clinical Neurology, vol. 6, no. 2, pp. 89-98, 2010.

[37] K. Esposito, M. Ciotola, B. Schisano et al., "Endothelial microparticles correlate with endothelial dysfunction in obese women," The Journal of Clinical Endocrinology \& Metabolism, vol. 91, no. 9, pp. 3676-3679, 2006.

[38] D. Burger, A. C. Montezano, N. Nishigaki, Y. He, A. Carter, and R. M. Touyz, "Endothelial microparticle formation by angiotensin II is mediated via Ang II receptor type I/NADPH oxidase/Rho kinase pathways targeted to lipid rafts," Arteriosclerosis, Thrombosis, and Vascular Biology, vol. 31, no. 8, pp. 1898-1907, 2011.

[39] D. Burger, D. G. Kwart, A. C. Montezano et al., "Microparticles induce cell cycle arrest through redox-sensitive processes in endothelial cells: implications in vascular senescence," 
Journal of the American Heart Association, vol. 1, no. 3, article e001842, 2012.

[40] A. D. Terrisse, N. Puech, S. Allart et al., "Internalization of microparticles by endothelial cells promotes platelet/endothelial cell interaction under flow," Journal of Thrombosis and Haemostasis, vol. 8, no. 12, pp. 2810-2819, 2010.

[41] H. A. Mostefai, A. Agouni, N. Carusio et al., "Phosphatidylinositol 3-kinase and xanthine oxidase regulate nitric oxide and reactive oxygen species productions by apoptotic lymphocyte microparticles in endothelial cells," Journal of Immunology, vol. 180, no. 7, pp. 5028-5035, 2008.

[42] S. Essayagh, J.-M. Xuereb, A.-D. Terrisse, L. Tellier-Cirioni, B. Pipy, and P. Sié, "Microparticles from apoptotic monocytes induce transient platelet recruitment and tissue factor expression by cultured human vascular endothelial cells via a redox-sensitive mechanism," Thrombosis and Haemostasis, vol. 98, no. 10, pp. 831-837, 2007.

[43] M. Mesri and D. C. Altieri, "Endothelial cell activation by leukocyte microparticles," The Journal of Immunology, vol. 161, no. 8, pp. 4382-4387, 1998.

[44] A. Scanu, N. Molnarfi, K. J. Brandt, L. Gruaz, J. M. Dayer, and D. Burger, "Stimulated T cells generate microparticles, which mimic cellular contact activation of human monocytes: differential regulation of pro- and anti-inflammatory cytokine production by high-density lipoproteins," Journal of Leukocyte Biology, vol. 83, no. 4, pp. 921-927, 2008.

[45] M. L. Mastronardi, H. A. Mostefai, F. Meziani, M. C. Martinez, P. Asfar, and R. Andriantsitohaina, "Circulating microparticles from septic shock patients exert differential tissue expression of enzymes related to inflammation and oxidative stress," Critical Care Medicine, vol. 39, no. 7, pp. 1739-1748, 2011.

[46] J. Mleczko, F. J. Ortega, J. M. Falcon-Perez, M. Wabitsch, J. M. Fernandez-Real, and S. Mora, "Extracellular Vesicles from Hypoxic Adipocytes and obese subjects reduce Insulin-Stimulated Glucose Uptake," Molecular Nutrition \& Food Research, vol. 62, no. 5, 2018.

[47] Y. Zhang, L. Shi, H. Mei et al., "Inflamed macrophage microvesicles induce insulin resistance in human adipocytes," Nutrition \& Metabolism, vol. 12, no. 1, p. 21, 2015.

[48] P. Diehl, A. Fricke, L. Sander et al., "Microparticles: major transport vehicles for distinct microRNAs in circulation," Cardiovascular Research, vol. 93, no. 4, pp. 633644, 2012.

[49] M. E. G. Kranendonk, D. P. V. de Kleijn, E. Kalkhoven et al., "Extracellular vesicle markers in relation to obesity and metabolic complications in patients with manifest cardiovascular disease," Cardiovascular Diabetology, vol. 13, no. 1, p. 37, 2014.

[50] Y. Choi, Y. Kwon, D. K. Kim et al., "Gut microbe-derived extracellular vesicles induce insulin resistance, thereby impairing glucose metabolism in skeletal muscle," Scientific Reports, vol. 5, no. 1, p. 15878, 2015.

[51] D. Faille, F. el-Assaad, A. J. Mitchell et al., "Endocytosis and intracellular processing of platelet microparticles by brain endothelial cells," Journal of Cellular and Molecular Medicine, vol. 16, no. 8, pp. 1731-1738, 2012.

[52] L. A. Mulcahy, R. C. Pink, and D. R. F. Carter, "Routes and mechanisms of extracellular vesicle uptake," Journal of Extracellular Vesicles, vol. 3, no. 1, 2014.
[53] A. S. Leroyer, P. E. Rautou, J. S. Silvestre et al., “CD40 ligand microparticles from human atherosclerotic plaques stimulate endothelial proliferation and angiogenesis: a potential mechanism for intraplaque neovascularization," Journal of the American College of Cardiology, vol. 52, no. 16, pp. 13021311, 2008.

[54] A. Mezentsev, R. M. H. Merks, E. O'Riordan et al., "Endothelial microparticles affect angiogenesis in vitro: role of oxidative stress," American Journal of Physiology-Heart and Circulatory Physiology, vol. 289, no. 3, pp. H1106-H1114, 2005.

[55] H. K. Kim, K. S. Song, J. H. Chung, K. R. Lee, and S. N. Lee, "Platelet microparticles induce angiogenesis in vitro," British Journal of Haematology, vol. 124, no. 3, pp. 376384, 2004.

[56] C. Yang, B. R. Mwaikambo, T. Zhu et al., "Lymphocytic microparticles inhibit angiogenesis by stimulating oxidative stress and negatively regulating VEGF-induced pathways," American Journal of Physiology-Regulatory, Integrative and Comparative Physiology, vol. 294, no. 2, pp. R467-R476, 2008.

[57] F. R. Formiga, B. Pelacho, E. Garbayo et al., "Sustained release of VEGF through PLGA microparticles improves vasculogenesis and tissue remodeling in an acute myocardial ischemia-reperfusion model," Journal of Controlled Release, vol. 147, no. 1, pp. 30-37, 2010.

[58] A. Ceriello and E. Motz, "Is oxidative stress the pathogenic mechanism underlying insulin resistance, diabetes, and cardiovascular disease? The common soil hypothesis revisited," Arteriosclerosis, Thrombosis, and Vascular Biology, vol. 24, no. 5, pp. 816-823, 2004.

[59] E. J. Henriksen, "Invited review: effects of acute exercise and exercise training on insulin resistance," Journal of Applied Physiology, vol. 93, no. 2, pp. 788-796, 2002.

[60] T. Guiraud, M. Gayda, M. Juneau et al., "A single bout of high-intensity interval exercise does not increase endothelial or platelet microparticles in stable, physically fit men with coronary heart disease," Canadian Journal of Cardiology, vol. 29, no. 10, pp. 1285-1291, 2013.

[61] M. Chanda, D. Nantakomol, D. Suksom, and A. Palasuwan, "Cell-derived microparticles after exercise in individuals with G6PD Viangchan," Clinical Hemorheology and Microcirculation, vol. 60, no. 2, pp. 241-251, 2015.

[62] M. D. Ross, A. L. Wekesa, J. P. Phelan, and M. Harrison, "Resistance exercise increases endothelial progenitor cells and angiogenic factors," Medicine and Science in Sports and Exercise, vol. 46, no. 1, pp. 16-23, 2014.

[63] S. Mobius-Winkler, T. Hilberg, K. Menzel et al., "Timedependent mobilization of circulating progenitor cells during strenuous exercise in healthy individuals," Journal of Applied Physiology, vol. 107, no. 6, pp. 1943-1950, 2009.

[64] S. K. Powers, L. L. Ji, A. N. Kavazis, and M. J. Jackson, "Reactive oxygen species: impact on skeletal muscle," Comprehensive Physiology, vol. 1, pp. 941-969, 2011.

[65] E. N. Wilhelm, J. Gonzalez-Alonso, C. Parris, and M. Rakobowchuk, "Exercise intensity modulates the appearance of circulating microvesicles with proangiogenic potential upon endothelial cells," American Journal of Physiology-Heart and Circulatory Physiology, vol. 311, no. 5, pp. H1297-H1310, 2016.

[66] M. Whitham, B. L. Parker, M. Friedrichsen et al., "Extracellular vesicles provide a means for tissue crosstalk during 
exercise," Cell Metabolism, vol. 27, no. 1, pp. 237-251.e4, 2018.

[67] P. Wahl, U. F. Wehmeier, F. J. Jansen et al., "Acute effects of different exercise protocols on the circulating vascular microRNAs -16, -21, and -126 in trained subjects," Frontiers in Physiology, vol. 7, p. 643, 2016.

[68] B. Toth, K. Nikolajek, A. Rank et al., "Gender-specific and menstrual cycle dependent differences in circulating microparticles," Platelets, vol. 18, no. 7, pp. 515-521, 2007.

[69] K. A. Lansford, D. D. Shill, A. B. Dicks, M. P. Marshburn, W. M. Southern, and N. T. Jenkins, "Effect of acute exercise on circulating angiogenic cell and microparticle populations," Experimental Physiology, vol. 101, no. 1, pp. 155$167,2016$.

[70] S. Sahoo, E. Klychko, T. Thorne et al., "Exosomes from human $\mathrm{CD} 34^{+}$stem cells mediate their proangiogenic paracrine activity," Circulation Research, vol. 109, no. 7, pp. 724-728, 2011.

[71] T. Asahara, T. Murohara, A. Sullivan et al., "Isolation of putative progenitor endothelial cells for angiogenesis," Science, vol. 275, no. 5302, pp. 964-966, 1997.

[72] C. Durrer, E. Robinson, Z. Wan et al., "Differential impact of acute high-intensity exercise on circulating endothelial microparticles and insulin resistance between overweight/ obese males and females," PLoS One, vol. 10, no. 2, article e0115860, 2015.

[73] A. Fard, C. H. Tuck, J. A. Donis et al., "Acute elevations of plasma asymmetric dimethylarginine and impaired endothelial function in response to a high-fat meal in patients with type 2 diabetes," Arteriosclerosis, Thrombosis, and Vascular Biology, vol. 20, no. 9, pp. 2039-2044, 2000.

[74] N. T. Jenkins, J. Padilla, L. J. Boyle, D. P. Credeur, M. H. Laughlin, and P. J. Fadel, "Disturbed blood flow acutely induces activation and apoptosis of the human vascular endothelium," Hypertension, vol. 61, no. 3, pp. 615-621, 2013.

[75] S. K. Malin, Z. Liu, E. J. Barrett, and A. Weltman, "Exercise resistance across the prediabetes phenotypes: impact on insulin sensitivity and substrate metabolism," Reviews in Endocrine and Metabolic Disorders, vol. 17, no. 1, pp. 81-90, 2016.

[76] M. Harrison, R. P. Murphy, P. L. O'Connor et al., “The endothelial microparticle response to a high fat meal is not attenuated by prior exercise," European Journal of Applied Physiology, vol. 106, no. 4, pp. 555-562, 2009.

[77] D. R. Blake, J. B. Meigs, D. C. Muller, S. S. Najjar, R. Andres, and D. M. Nathan, "Impaired glucose tolerance, but not impaired fasting glucose, is associated with increased levels of coronary heart disease risk factors: results from the Baltimore Longitudinal Study on Aging," Diabetes, vol. 53, no. 8, pp. 2095-2100, 2004.

[78] B. H. Goodpaster, D. E. Kelley, R. R. Wing, A. Meier, and F. L. Thaete, "Effects of weight loss on regional fat distribution and insulin sensitivity in obesity," Diabetes, vol. 48, no. 4, pp. 839-847, 1999.

[79] S. K. Malin, R. Gerber, S. R. Chipkin, and B. Braun, "Independent and combined effects of exercise training and metformin on insulin sensitivity in individuals with prediabetes," Diabetes Care, vol. 35, no. 1, pp. 131-136, 2012.

[80] S. K. Malin, J. M. Haus, T. P. J. Solomon, A. Blaszczak, S. R. Kashyap, and J. P. Kirwan, "Insulin sensitivity and metabolic flexibility following exercise training among different obese insulin-resistant phenotypes," American journal of Physiology-Endocrinology and Metabolism, vol. 305, no. 10, pp. E1292-E1298, 2013.

[81] T. P. J. Solomon, S. K. Malin, K. Karstoft, J. M. Haus, and J. P. Kirwan, "The influence of hyperglycemia on the therapeutic effect of exercise on glycemic control in patients with type 2 diabetes mellitus," JAMA Internal Medicine, vol. 173, no. 19, pp. 1834-1836, 2013.

[82] P. Clarkson, H. E. Montgomery, M. J. Mullen et al., "Exercise training enhances endothelial function in young men," Journal of the American College of Cardiology, vol. 33, no. 5, pp. 1379-1385, 1999.

[83] D. L. Swift, J. Y. Weltman, J. T. Patrie et al., "Predictors of improvement in endothelial function after exercise training in a diverse sample of postmenopausal women," Journal of Women's Health, vol. 23, no. 3, pp. 260-266, 2014.

[84] N. Gokce, J. A. Vita, D. S. Bader et al., "Effect of exercise on upper and lower extremity endothelial function in patients with coronary artery disease," The American Journal of Cardiology, vol. 90, no. 2, pp. 124-127, 2002.

[85] R. Hambrecht, A. Wolf, S. Gielen et al., "Effect of exercise on coronary endothelial function in patients with coronary artery disease," New England Journal of Medicine, vol. 342, no. 7, pp. 454-460, 2000.

[86] L. Bruyndonckx, V. Y. Hoymans, A. De Guchtenaere et al., "Diet, exercise, and endothelial function in obese adolescents," Pediatrics, vol. 135, no. 3, pp. e653-e661, 2015.

[87] S. La Vignera, R. Condorelli, E. Vicari, R. D'agata, and A. Calogero, "Aerobic physical activity improves endothelial function in the middle-aged patients with erectile dysfunction," The Aging Male, vol. 14, no. 4, pp. 265272, 2011.

[88] J. S. Kim, B. Kim, H. Lee et al., "Shear stress-induced mitochondrial biogenesis decreases the release of microparticles from endothelial cells," American Journal of PhysiologyHeart and Circulatory Physiology, vol. 309, no. 3, pp. H425H433, 2015.

[89] J. Kretzschmar, D. M. Babbitt, K. M. Diaz et al., "A standardized exercise intervention differentially affects premenopausal and postmenopausal African-American women," Menopause, vol. 21, no. 6, pp. 579-584, 2014.

[90] D. M. Babbitt, K. M. Diaz, D. L. Feairheller et al., "Endothelial activation microparticles and inflammation status improve with exercise training in African Americans," International Journal of Hypertension, vol. 2013, Article ID 538017, 8 pages, 2013.

[91] J. Pitha, I. Kralova Lesna, P. Stavek et al., "Effect of exercise on markers of vascular health in renal transplant recipients," Physiological Research, vol. 64, no. 6, pp. 945949, 2015.

[92] I. Y. Oh, C. H. Yoon, J. Hur et al., "Involvement of E-selectin in recruitment of endothelial progenitor cells and angiogenesis in ischemic muscle," Blood, vol. 110, no. 12, pp. 38913899, 2007.

[93] M. E. Mendelsohn, "Protective effects of estrogen on the cardiovascular system," The American Journal of Cardiology, vol. 89, no. 12, pp. 12-17, 2002.

[94] N. Z. M. Eichner, N. M. Gilbertson, J. M. Gaitan et al., "Low cardiorespiratory fitness is associated with higher microparticle counts in obese adults," Physiological Reports, vol. 6, no. 10, article e13701, 2018. 
[95] E. M. Van Craenenbroeck, G. Frederix, N. Pattyn et al., "Effects of aerobic interval training and continuous training on cellular markers of endothelial integrity in coronary artery disease: a SAINTEX-CAD substudy," American Journal of Physiology-Heart and Circulatory Physiology, vol. 309, no. 11, pp. H1876-H1882, 2015.

[96] I. J. Kullo, M. Khaleghi, and D. D. Hensrud, "Markers of inflammation are inversely associated with $\mathrm{VO}_{2} \max$ in asymptomatic men," Journal of Applied Physiology, vol. 102, no. 4, pp. 1374-1379, 2007.

[97] X. Wang, T. You, K. Murphy, M. F. Lyles, and B. J. Nicklas, "Addition of exercise increases plasma adiponectin and release from adipose tissue," Medicine and Science in Sports and Exercise, vol. 47, no. 11, pp. 2450-2455, 2015.

[98] A. Silveira, F. Karpe, H. Johnsson, K. A. Bauer, and A. Hamsten, "In vivo demonstration in humans that large postprandial triglyceride-rich lipoproteins activate coagulation factor VII through the intrinsic coagulation pathway," Arteriosclerosis, Thrombosis, and Vascular Biology, vol. 16, no. 11, pp. 1333-1339, 1996.

[99] Y. C. Chen, C. W. Ho, H. H. Tsai, and J. S. Wang, "Interval and continuous exercise regimens suppress neutrophilderived microparticle formation and neutrophil-promoted thrombin generation under hypoxic stress," Clinical Science, vol. 128, no. 7, pp. 425-436, 2015.

[100] J. S. Wang, Y. L. Chang, Y. C. Chen, H. H. Tsai, and T. C. Fu, "Effects of normoxic and hypoxic exercise regimens on monocyte-mediated thrombin generation in sedentary men," Clinical Science, vol. 129, no. 4, pp. 363-374, 2015.

[101] Y. Yuana, R. M. Bertina, and S. Osanto, "Pre-analytical and analytical issues in the analysis of blood microparticles," Thrombosis and Haemostasis, vol. 105, no. 03, pp. 396-408, 2011.

[102] S. H. van Ierssel, E. M. Van Craenenbroeck, V. M. Conraads et al., "Flow cytometric detection of endothelial microparticles (EMP): effects of centrifugation and storage alter with the phenotype studied," Thrombosis Research, vol. 125, no. 4, pp. 332-339, 2010.

[103] F. Mobarrez, J. Antovic, N. Egberg et al., "A multicolor flow cytometric assay for measurement of platelet-derived microparticles," Thrombosis Research, vol. 125, no. 3, pp. e110-e116, 2010.

[104] A. G. Kriebardis, M. H. Antonelou, H. T. Georgatzakou, V. L. Tzounakas, K. E. Stamoulis, and I. S. Papassideri, "Microparticles variability in fresh frozen plasma: preparation protocol and storage time effects," Blood Transfusion, vol. 14, no. 2, pp. 228-237, 2016.

[105] E. Dey-Hazra, B. Hertel, T. Kirsch et al., "Detection of circulating microparticles by flow cytometry: influence of centrifugation, filtration of buffer, and freezing," Vascular Health and Risk Management, vol. 6, pp. 1125-1133, 2010.

[106] EV-TRACK Consortium, J. van Deun, P. Mestdagh et al., "EV-TRACK: transparent reporting and centralizing knowledge in extracellular vesicle research," Nature Methods, vol. 14, no. 3, pp. 228-232, 2017.

[107] N. Arraud, R. Linares, S. Tan et al., "Extracellular vesicles from blood plasma: determination of their morphology, size, phenotype and concentration," Journal of Thrombosis and Haemostasis, vol. 12, no. 5, pp. 614-627, 2014.

[108] U. Erdbrügger, C. K. Rudy, M. E. Etter et al., "Imaging flow cytometry elucidates limitations of microparticle analysis by conventional flow cytometry," Cytometry Part A, vol. 85, no. 9, pp. 756-770, 2014.

[109] C. Théry, M. Ostrowski, and E. Segura, "Membrane vesicles as conveyors of immune responses," Nature Reviews Immunology, vol. 9, no. 8, pp. 581-593, 2009.

[110] D. W. Greening, S. K. Gopal, R. Xu, R. J. Simpson, and $\mathrm{W}$. Chen, "Exosomes and their roles in immune regulation and cancer," Seminars in Cell \& Developmental Biology, vol. 40, pp. 72-81, 2015.

[111] G. Camussi, M. C. Deregibus, S. Bruno, V. Cantaluppi, and L. Biancone, "Exosomes/microvesicles as a mechanism of cell-to-cell communication," Kidney International, vol. 78, no. 9, pp. 838-848, 2010.

[112] C. Fruhbeis, S. Helmig, S. Tug, P. Simon, and E. M. KramerAlbers, "Physical exercise induces rapid release of small extracellular vesicles into the circulation," Journal of Extracellular Vesicles, vol. 4, no. 1, article 28239, 2015.

[113] A. Safdar, A. Saleem, and M. A. Tarnopolsky, "The potential of endurance exercise-derived exosomes to treat metabolic diseases," Nature Reviews Endocrinology, vol. 12, no. 9, pp. 504-517, 2016.

[114] Y. Bei, T. Xu, D. Lv et al., "Exercise-induced circulating extracellular vesicles protect against cardiac ischemia-reperfusion injury," Basic Research in Cardiology, vol. 112, no. 4, p. 38, 2017.

[115] S. Mora, N. Cook, J. E. Buring, P. M. Ridker, and I. M. Lee, "Physical activity and reduced risk of cardiovascular events: potential mediating mechanisms," Circulation, vol. 116, no. 19, pp. 2110-2118, 2007.

[116] S. el Andaloussi, I. Mäger, X. O. Breakefield, and M. J. A. Wood, "Extracellular vesicles: biology and emerging therapeutic opportunities," Nature Reviews Drug Discovery, vol. 12, no. 5, pp. 347-357, 2013. 


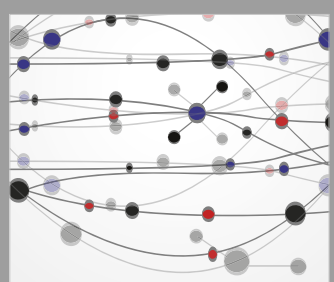

The Scientific World Journal
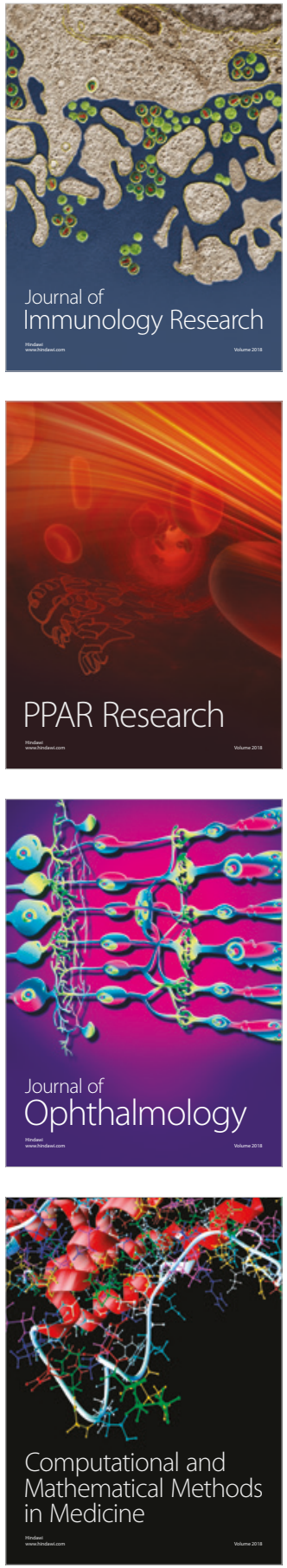

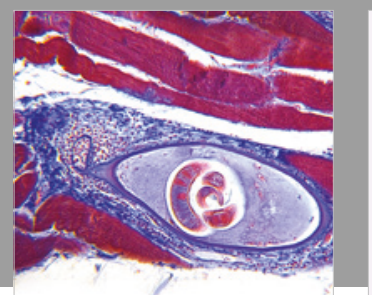

Gastroenterology Research and Practice

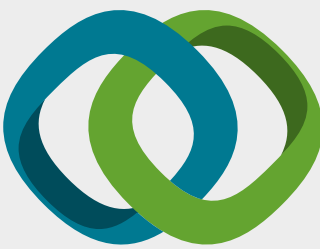

\section{Hindawi}

Submit your manuscripts at

www.hindawi.com
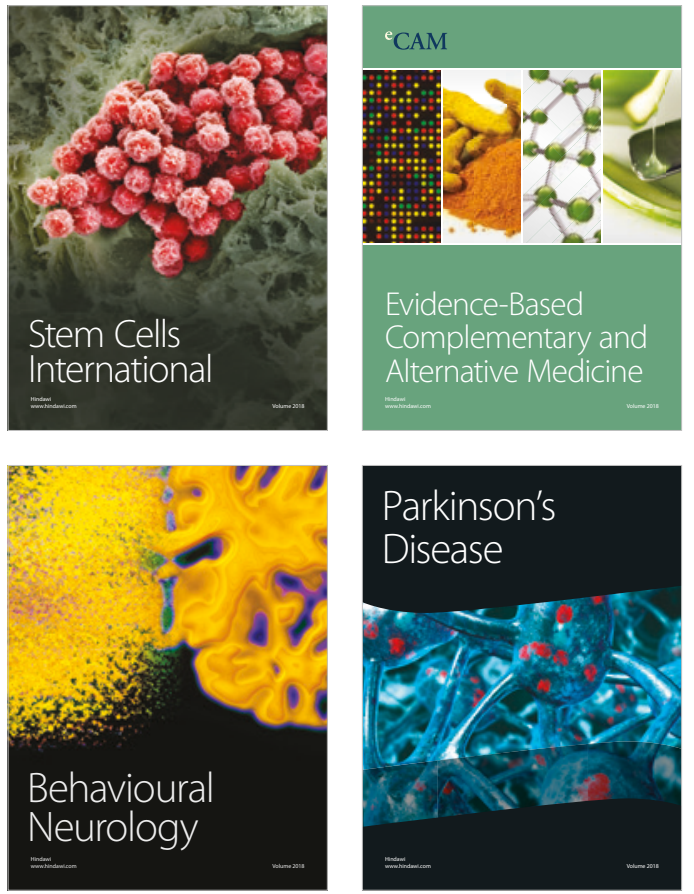

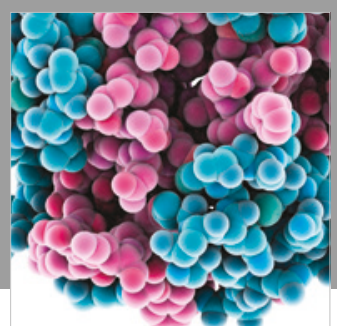

ournal of

Diabetes Research

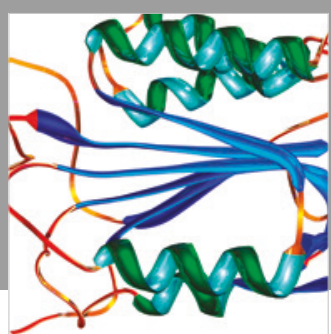

Disease Markers
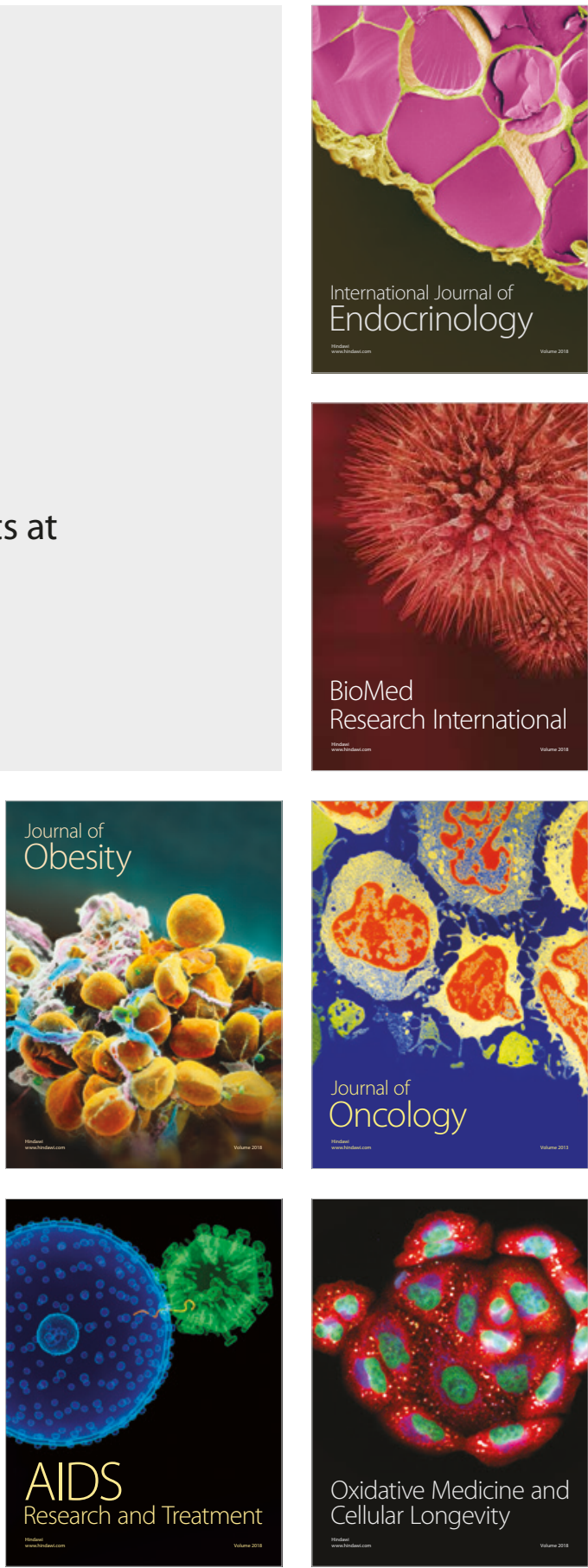